\title{
Influences of MHC Class II Haplotypes on Avian Influenza Traits in Thai Indigenous Chicken
}

\author{
Kalaya Boonyanuwat ${ }^{1,2}$, Sawat Thummabutra ${ }^{2}$, Neramit Sookmanee ${ }^{1}$, \\ Voravit Vatchavalkhu ${ }^{3}$, Voravit Siripholvat ${ }^{1}$ and Tadayoshi Mitsuhashi ${ }^{4}$ \\ ${ }^{1}$ Department of Animal Science, Faculty of Agriculture, Kasetsart University, \\ Kamphangsan, Nakhornpathom Province, Thailand \\ ${ }^{2}$ Division of Livestock Breeding, Department of Livestock Development, Ministry of \\ Agriculture and Cooperative, Rachathevee, Bangkok, Thailand \\ ${ }^{3}$ Department of Pathology, Faculty of Veterinary Medicine, Kasetsart University, \\ Kamphangsan, Nakhornpathom Province, Thailand \\ ${ }^{4}$ Department of Physiology and Genetic Regulation, National Institute of \\ Agrobiological Sciences, Japan
}

\begin{abstract}
Natural infections with influenza viruses have been reported in a variety of animal species including human, pigs, horses, sea mammals, mustelids and birds. Occasionally devastating pandemics occur in domestic chickens (broiler and layers) and human. During November 2003 to March 2004 in many countries in Asia, there are outbreaks of H5N1 avian influenza virus, causing of death of infected patients and devastated poultry industry. Some groups of Thai indigenous chickens are survivable recommended as resistance. These traits were related to immunogenetics, especially, the major histocompatibility complex (MHC) class I and class II molecules. The chicken MHC class II was investigated as candidate genes for avian influenza resistance. Seven hundred and thirty Thai indigenous chickens of small holder farms in the rural area of avian influenza outbreaks in the central part of Thailand were used in this study. They were separated into two groups, 340 survivable chickens and 390 dead chickens (resistance and susceptible). Genomic DNA were precipitated from blood samples and feathers. Diluted DNA was amplified to identify MHC haplotype. Data were statistically analyzed by $\chi 2$ analysis to test significant differences of influences of MHC class II haplotypes on avian influenza traits. The results represented ten MHC class II haplotypes, A9, B12, B13, B14, B19, B21, B2, B4, B5, and B6, and included eighteen of their crossbred. The homozygous B21 from these collected samples had 100 percent of survival rate and they were the major survival group. In addition, the heterozygous B21 also showed high survival rate because of co-dominant expression of these genes. In the other way, the homozygous B13 had 100 percent of mortality rate and they were the major group of high mortality rate. These results confirmed that MHC class II haplotypes influenced on avian influenza resistant traits in Thai indigenous chicken. The MHC genes can be used as genetic markers to improve disease resistant traits in chicken.
\end{abstract}

Key words : avian influenza virus, major histocompatibility complex, thai indigenous chicken

\section{Introduction}

The chicken MHC lies on chromosome 16, which is a microchromosome. It was included various linked multigene families of highly polymorphic genes $(\mathrm{Li}$ et al., 1997). It was succeedingly discovered to contain three loci, BF, BL, and BG (Pink et al., 1977), producing class I, II, and IV antigens, which

Received : June 17, 2005, Accepted : December 5, 2005

Correspondence to : Miss Kalaya Boonyanuwat, Department of Livestock Development, Rachathevi, Bangkok, 10400, Thailand

Tel : 66-6-6048225 Fax : 66-2-6534922 E-mail : kalayabo@yahoo.com 
expressed on the surface of all nucleated cells, immunological cells, and erythrocytes respectively (Ewert et al., 1980 ; Nordskog et al., 1987). MHC worked as antigen presenting to $\mathrm{T}$ lymphocytes as central role of immune system (Abbas et al., 2000). It was first identified by the ability of leukocytes to give strong graft rejection. There is some evidence for different MHC haplotypes having different competence in graft vs. host responses (GVHR), and this was conformed as a mechanism for resistance to Marek's disease ; i.e., less proliferation would decrease the chance of lymphoma development, but may also lead to a general decrease in $\mathrm{T}$ cell responses (Pazderka et al., 1975). However, there is no research about association of $\mathrm{MHC}$ and avian influenza. It is very important to find candidate genes relating to avian influenza as genetic markers for disease resistant traits improvement.

During November 2003 to March 2004 in many countries in Asia, there were outbreaks of H5N1 avian influenza virus, causing of death of infected patients and devastated poultry industry. Avian influenza outbreaks could be difficult to control and often caused major economic impacts for poultry farmers in affected countries, since mortality rates were high and infected fowl generally might be destroyed in order to prevent the spread of the disease. As a result of ongoing outbreak in Asia, FAO estimated that around 20-25 million birds had been destroyed. For this reason, the local economies of both commercial poultry operations and smallholders were devastated, especially in Thailand, where the industry was heavily reliant on trade. In 2003, poultry exports from Thailand accounted for nearly 7 percent of global poultry meat trade, with an export value of approximately US $\$ 1$ billion. Avian influenza outbreak severely decreased frozen poultry meat exportation. The most importance of this outbreak, it caused of death of infected patients in Thailand and Vietnam. Thus, disease resistance was an important economical consideration to poultry industry. During this outbreak, some groups of Thai indigenous chickens were survivable recommended as resistance. This situation indicated that disease resistant traits can be improved genetic selection of genetic markers related to these traits.

Insecurity to disease also might destroy Thai domestic supplies as well as exports of this important food commodity. An interesting alternative ap- proach to standard disease control methods would be selective breeding to increase disease resistance in livestock. Genetic resistance to disease involved many facets of the body's defense system and their interactions and was extremely complex. Disease resistance research had included measurement of genetic control of disease losses, estimation of heritabilities, and characterization of breed or strain differences. By the reason of production traits genetic improvement made high power of genetic selection for high production traits, the result was down for disease resistant traits. Also, by the way of negative correlations between production traits and disease resistant traits, in addition that disease resistant traits had low heritability, this made difficult to use conventional breeding to improve disease resistant traits. New opportunities to improve our understanding of the genetic nature of disease resistance occur through the recent advances in molecular biology, gene mapping, and immunology and make selection for disease resistance possible in the future. However, genetic considerations included with testing and selection for disease resistance and improved immune responsiveness would need knowledge of the genetic correlations among disease resistance and immune responsiveness and production traits. However, there was a little research in this field.

The current focus was on the genetic makeup of the chicken, specifically the major histocompatibility complex (MHC). Due to the involvement in immune responses, the MHC had a large influence on resistance or susceptibility to disease. This promoted the identification of specific chicken MHC haplotypes for disease resistance. Knowledge of the gene might also suggest improved pharmaceutical or immunological therapies. The objective of the present study was to investigate influences of MHC class II haplotypes on avian influenza traits in Thai indigenous chicken to support the idea of disease resistant traits improvement, animal welfare, safe production, and safe food.

\section{Materials and Methods}

\section{Chicken}

The chickens used in this research were seven hundred and thirty Thai indigenous chickens in rural area of central part of Thailand in the area of avian influenza outbreak such as Ayuthaya, Kanchanaburi, Nakhon Pathom, Singburi, and Suphanburi prov- 
ince, composed of 390 and 340 dead and survived chickens respectively. There was no outbreak of avian influenza in the former time. Chickens never had avian influenza vaccine. They were kept from small holder farms that there were dead and survivable chickens in each farm from avian influenza. About survivable chickens, some were not sick and some were sick, but there were outbreak in every farm of blood collected. Some of sick chickens were died and some were survived. Each farm was random to collect chicken blood for titer testing.

\section{Chicken DNA Extraction}

Blood and feather samples were collected from two groups of chickens, survivors and deads from outbreak area. They were used to extract genomic DNA. Extraction of DNA from blood was performed by $0.5 \mathrm{~m} l$ of chicken blood collected from the wing vein and kept in micro-tube with EDTA. Blood was treated by lysis buffer, consisted of $\mathrm{NaCl}$, Tris- $\mathrm{HCl}$ ( $\mathrm{pH} 8.0)$, EDTA, SDS, left in $55^{\circ} \mathrm{C}$ incubator 10 minutes, and added by proteinase $\mathrm{K}$, left in $55^{\circ} \mathrm{C}$ incubator 2 hours. The samples were treated with the combination of phenol : chloroform : isoamyl alcohol (25:24:1), mixed, and separated. The upper layer were phenol-extracted, centrifuged, upper layer collected, and added by $95 \%$ ethanol, DNA sample were collected in micro-tube, washed by $70 \%$ ethanol two times, and left to remove ethanol. The DNA samples were added by TE buffer, consisted of $10 \mathrm{mM}$ Tris and $1 \mathrm{mM}$ EDTA, $\mathrm{pH} 7.0$, and kept at $-40^{\circ} \mathrm{C}$. DNA extracted from feather was performed by using $50 \mathrm{mg}$ clean individual tip feather. Tip feather was cut into small pieces and soaked in guanidine solution, left in $55^{\circ} \mathrm{C}$ incubator $>18$ hours, and added by proteinase $\mathrm{K}$, left in $55^{\circ} \mathrm{C}$ incubator 2 hours. The samples were treated with the combination of phenol : chloroform : isoamyl alcohol (25:24:1), mixed, and separated. The upper layer were phenol-extracted, centrifuged, upper layer collected, precipitate by 2 times volume of $95 \%$ ethanol added with $10 \%$ of $3 \mathrm{M}$ sodium acetate, and $12000 \mathrm{rpm}$ centrifugation. Precipitant was collected and washed by $70 \%$ ethanol two times, and left to remove ethanol (modified from Griffiths and Tlwarl, 1995 ; Sambrook and Russell, 2002). The DNA samples were added by distilled water, and kept at $-40^{\circ} \mathrm{C}$.

Each DNA sample concentration was measured by the comparision between the concentration of
DNA band of agarose gel and standard concentration. Genomic DNA sample were mixed with steamed distilled water for appropriate concentration $(20 \mathrm{ng} / \mu \mathrm{l})$, and kept.

\section{PCR Amplification}

Genomic DNA from chickens, extracted by previous method were used to identify MHC haplotype by PCR of microsatellite marker, LEI0258. DNA samples were amplified by using forward and reverse primers (5'-CACGCAGCAGAACTTGGTAAGG$3^{\prime}$ and $5^{\prime}$-AGCTGTGCTCAGTCCTCAGTGC-3') (McConnell et al., 1999). This microsatellite was tetranucleotide microsatellite near $\mathrm{BL} \beta$ I on microchromosome 16. Each $15 \mu \mathrm{l}$ reaction contained 20 ng of DNA, $0.5 \mu \mathrm{M}$ of each primer, $1.9 \mathrm{mM} \mathrm{MgCl}_{2}$, $0.2 \mathrm{mM}$ of each dNTP and 1 unit of Taq DNA polymerase in the supplied buffer (final concentration : $20 \mathrm{mM}\left(\mathrm{NH}_{4}\right)_{2} \mathrm{SO}_{4}, 75 \mathrm{mM}$ Tris- $\mathrm{HCl} \mathrm{pH} 9.0$, $0.01 \%(\mathrm{w} / \mathrm{v})$ Tween). PCR amplification of DNA was performed using Touchdown PCR in a PTC$100^{\mathrm{TM}}$ Programmable Thermal Controller using the reaction profile of initial denaturation of $94^{\circ} \mathrm{C} 3 \mathrm{~min}$, denaturation of $94^{\circ} \mathrm{C} 0.45 \mathrm{~min}$, annealing $59^{\circ} \mathrm{C} 0.45$ min, temperature increment $-1{ }^{\circ} \mathrm{C} /$ cycle, extension of $72^{\circ} \mathrm{C} 1 \mathrm{~min}$, for 5 cycle, denaturation of $94^{\circ} \mathrm{C} 0.45$ min, annealing $54^{\circ} \mathrm{C} 0.45 \mathrm{~min}$, extension of $72^{\circ} \mathrm{C} 1$ min, for 25 cycle, and final extension of $72^{\circ} \mathrm{C} 10 \mathrm{~min}$. Each group of genomic DNA separated by LEI0258 typing were partial sequencing of BL $\beta \mathrm{I}$ exon 2 PCR (Forward primer 5' GTGCCCGCAGCGTTCTTC 3', Reverse primer 5' TCCTCTGCACCGTGAAGG $3^{\prime}$ (Goto et al., 2002). Each $20 \mu \mathrm{l}$ reaction contained $20 \mathrm{ng}$ of DNA, $0.5 \mu \mathrm{M}$ of each primer, $1.9 \mathrm{mM}$ $\mathrm{MgCl}_{2}, 0.2 \mathrm{mM}$ of each $\mathrm{dNTP}$ and 1 unit of Taq DNA polymerase in the supplied buffer. PCR amplification of DNA was performed in a PTC- $100^{\mathrm{TM}}$ Programmable Thermal Controller using the reaction profile of initial denaturation of $94^{\circ} \mathrm{C} 3 \mathrm{~min}$, denaturation of $94^{\circ} \mathrm{C} 0.45 \mathrm{~min}$, annealing $54^{\circ} \mathrm{C} 0.45$ min, extension of $72^{\circ} \mathrm{C} 1 \mathrm{~min}$, for 35 cycle, and final extension of $72^{\circ} \mathrm{C} 10 \mathrm{~min}$. Aliquots of the PCR reactions were checked for robustness using $2 \%$ agarose gel electrophoresis before proceeding to automated sequencing.

Each group from LEI0258 typing was standardized by partial sequencing of $\mathrm{BL} \beta$ genes to identify MHC haplotype. 


\section{Estimation of Influences of MHC Haplotypes on Avian Influenza}

Data were statistical analyzed by $\chi 2$ analysis to test significant differences of influences of MHC class II haplotypes on avian influenza traits in Thai indigenous chicken.

\section{Results and Discussion}

\section{Situation of Avian Influenza Outbreaks in Thailand}

Avian influenza was caused by avian influenza virus type A, capsulated RNA virus of Orthomyxoviridae family. It has 2 specific surface antigens, haemagglutinin $(\mathrm{H}, \mathrm{H} 1-\mathrm{H} 15)$ and neuraminidase (N, N1-N9). During November 2003 to March 2004 in many country in Asia, such as Cambodia, China, Hong Kong, Indonesia, Japan, Korea, Loa, Vietnam, and Thailand, there were outbreaks of avian influenza, especially in Vietnam and Thailand, strain of $\mathrm{H} 5 \mathrm{~N} 1$, causing of death of infected patients and devastated poultry industry. The H5N1 strain had a different genetic sequence and therefore is believed to come from a different source. It is violent pathogenic Avian Influenza. In Thailand, there are ongoing outbreaks of avian influenza. It devastated to local economies and to both commercial poultry operations and smallholders. Chicken prices are down slightly this year in the EU. While a ban on Thai chicken will leave a deficit in the market for proceed white meat, it is likely that the Brazilians, a competitive producer of similar type of product, will move to supply the gap. In the Japanese market, domestic poultry supplies are dropping as avian influenza infected flocks are disposed of and imports are banned from Thailand (Thailand accounts for thirty percent of Japanese poultry imports). This will push prices of all meats higher. Interestingly, some of Thai indigenous chickens survived from these outbreaks. It meant that these chickens resisted to avian influenza. They were suitable to use as genetic resources for genetic improvement of virulent disease resistant traits in poultry industry in Thailand.

\section{MHC Class II Haplotypes Genotyping}

MHC class II haplotypes genotyping was used the previous method. The results represented ten $\mathrm{MHC}$ class II haplotypes, A9, B12, B13, B14, B19, B21, B 2, B4, B5, and B6, and included eighteen of their crossbred. Haplotype of A9 of MHC class II was haplotype in broiler chicken found by $\mathrm{Li}$ et al.
(1999), different from standard haplotypes in White Leghorn chicken. Standard haplotype in White Leghorn chicken preceded with the letter ' $\mathrm{B}$ ' and followed by numeric. Many scientists suggested that nucleotide sequencing of $\mathrm{MHC}$ haplotypes from different breeds were different, because of cross-reaction of serological reagent of White Leghorn using in broiler chicken (Li et al., 1999). B2-B21 MHC class II haplotypes were identity to standard haplotypes of White Leghorn chicken.

\section{Influences of MHC Class II Gene Polymorphisms to Avian Influenza Traits}

The MHC haplotypes were identified in Thai indigenous chickens of small holder farms in the rural area of avian influenza outbreaks in the central part of Thailand represented 28 groups of homozygous and heterozygous haplotypes (Table 1).

The B21 haplotype in MHC class II was the strongest resistant haplotype. The haplotype of B21 survived 100 percents in class I (data not shown). The B12 haplotype was found in dead chickens, recommended as susceptible group. The B12 haplotype in many reseaches were the same case in as this study. It was susceptible to disease (not all disease) (Bacon, 1987). In MHC class II haplotypes, similarly to MHC class I, homozygous B21 haplotype chicken survived 100 percents and they were major group, also to their crossbred with other haplotypes were high survival percentage, because of effected expression as co-dominant of this gene. The B14 homozygous haplotypes and their heterozygotes were high survival. In addition, A9 haplotype was 90 percents survival rate. The sequences of B21, B 14 , and $\mathrm{A} 9$ haplotype at exon 2 of $\mathrm{BL} \beta$ were almost similar. This region of gene produced protein as pathogen binding site. This region was highly polymorphic and specific to pathogen in each haplotypes. The B13 haplotype were 100 percents of mortality rate, and they were the major group of dead chickens. The same as B19 haplotype, they were 100 percents dead. However, their heterozygous haplotypes were not 100 percent survived, or 100 percent dead, because the effect of co-dominant gene expression.

Thai indigenous chickens of small holder farms in the rural area were raised according to natural environment. They were selected by natural selection. The strong chickens were alive and reproductive. The susceptible chickens were culled by nature 
Table 1. Influences of MHC class II gene polymorphisms to avian influenza traits

\begin{tabular}{|c|c|c|}
\hline Haplotypes ${ }^{1 /}$ & Number of chicken ${ }^{2 /}$ & $\%$ survival $^{3}$ \\
\hline \multicolumn{3}{|l|}{ LHK } \\
\hline A9A9 & 31 & $90.32^{\mathrm{a}}$ \\
\hline B12B12 & 39 & $0.00^{\mathrm{c}}$ \\
\hline B12B13 & 4 & $0.00^{\mathrm{c}}$ \\
\hline $\mathrm{B} 12 \mathrm{~B} 2$ & 24 & $66.67^{\mathrm{b}}$ \\
\hline B13B13 & 71 & $0.00^{\mathrm{c}}$ \\
\hline B13B2 & 6 & $0.00^{\mathrm{c}}$ \\
\hline B14B14 & 8 & $100.00^{\mathrm{a}}$ \\
\hline B14B19 & 4 & $0.00^{\mathrm{c}}$ \\
\hline B14B2 & 3 & $100.00^{\mathrm{a}}$ \\
\hline B19B19 & 5 & $0.00^{\mathrm{c}}$ \\
\hline B21B21 & 74 & $100.00^{\mathrm{a}}$ \\
\hline B21B4 & 5 & $20.00^{\mathrm{c}}$ \\
\hline B2B2 & 6 & $66.67^{\mathrm{b}}$ \\
\hline B2B21 & 10 & $90.00^{\mathrm{a}}$ \\
\hline B2B5 & 16 & $43.75^{\mathrm{b}}$ \\
\hline B4B4 & 4 & $50.00^{\mathrm{b}}$ \\
\hline B5B5 & 3 & $66.67^{\mathrm{b}}$ \\
\hline \multicolumn{3}{|l|}{ PHD } \\
\hline A9A9 & 31 & $90.32^{\mathrm{a}}$ \\
\hline B12B12 & 92 & $0.00^{\mathrm{c}}$ \\
\hline B12B13 & 4 & $0.00^{c}$ \\
\hline $\mathrm{B} 12 \mathrm{~B} 2$ & 24 & $66.67^{\mathrm{b}}$ \\
\hline B13B13 & 71 & $0.00^{\mathrm{d}}$ \\
\hline B13B2 & 6 & $0.00^{\mathrm{d}}$ \\
\hline B14B14 & 2 & $100.00^{\mathrm{a}}$ \\
\hline B14B19 & 4 & $0.00^{\mathrm{d}}$ \\
\hline B14B2 & 3 & $100.00^{\mathrm{a}}$ \\
\hline B19B19 & 5 & $0.00^{\mathrm{d}}$ \\
\hline B21B21 & 103 & $100.00^{\mathrm{a}}$ \\
\hline B21B4 & 5 & $20.00^{\mathrm{d}}$ \\
\hline B2B2 & 6 & $66.67^{\mathrm{b}}$ \\
\hline B2B21 & 7 & $85.71^{\mathrm{a}}$ \\
\hline B2B5 & 16 & $43.75^{c}$ \\
\hline B4B4 & 4 & $50.00^{\mathrm{b}}$ \\
\hline B5B5 & 3 & $66.67^{\mathrm{b}}$ \\
\hline
\end{tabular}

${ }^{1 /}$ LHK $=$ Leung-Hahng-Kow chicken, PHD $=$ Pradoo-Hahng-Dam

${ }^{2 /}$ Data not shown for minor group chicken.

${ }^{3 /}$ The different letter in same class of MHC means highly significant difference $(\mathrm{P}<0.01)$.

passed through many generations, dead, and extinct.

Further experiment, combination between MHC class I and II affecting on avian influenza will be apparently detected. The various combination among haplotypes showed various levels of disease resistance. The regions of $\mathrm{BL} \beta \mathrm{I}$ exon 2 of $\mathrm{MHC}$ class II haplotypes were specific to pathogen, pathogen binding site, so MHC class II haplotypes were highly polymorphism in disease resistant traits (Livant et al., 2001).

After the outbreaks, many of chickens including survived Thai indigenous chickens, were destroyed to eradicate avian influenza. It is suitable to short term controlling. In long term controlling, it is better to improve disease resistant traits in poultry by using candidate genes of disease resistance as genetic marker associating with conventional breeding. Disease resistant trait improvement can't process in only conventional breeding according to negative correlation between production traits and disease resistant traits. High intensity of selection of production traits compresses disease resistant traits (Rothschild, 1989). In conventional breeding, step of progeny test, it can't challenge pathogens to select sire or dam. Therefore, genetic markers of disease resistant genes such as MHC genes, are suitable to improve disease resistant traits.

The MHC class II genes associated to avian influenza trait in Thai indigenous chickens. There are polymorphisms of these genes. The MHC genes can be used as genetic markers to improve disease resistant traits in chickens (indigenous chicken, broiler, and layers) for disease prevention. Finally, poultry industry has high standards in the world for raising healthy livestock and providing consumers with safe products.

\section{Acknowledgments}

The authors thank to Mrs. Sommart Suwanmajo and Mrs. Udomsri Intharachote for sample providing. Thanks also go to Center for Agricultural Biotechnology for laboratory supports.

\section{References}

Abbas AK, Lichtman AH and Pober JS. Cellular and molecular immunology. $4^{\text {th }}$ ed. WB Saunders company. Pennsylvania. pp. 97-132. 2000.

Bacon LD. Influence of the major histocompatibility complex on disease resistance and productivity. Poultry Science, 66, 802-811. 1987.

Ewert DL, Gilmour DG, Briles WE and Cooper MD. Genetics of Ia-like alloantigens in chickens and linkage with B major histocompatibility complex. Immunogenetics, 10 , 169-174. 1980.

Fulton JE, Thacker EL, Bacon LD and Hunt HD. Functional analysis of avian class I (BFIV) glycoproteins by epitope tagging and mutagenesis in vitro.European Journal of Immunology, 25, 2069-2076. 1995.

Goto RM, Afanassieff M, Ha J, Iglesias GM, Ewald SJ, Briles WE and Miller MM. DNA-based major histocompatibility complex $B$ typing. Poultry Science, 81, 1832-1841. 2002.

Griffiths R and Tlwarl B. Sex of the last wild Spix's macaw. Nature, 375, 454. 1995.

Jacob JP, Milne S, Beck S and Kaufman J. The major and a minor class II $\beta$-chain (B-LB) gene flank the Tapasin 
gene in the B-F/B-L region of the chicken major histocompatibility complex. Immunogenetics, 51, 138147. 2000.

Li L, Johnson LW and Ewald SJ. Molecular characterization of major histocompatibility complex $(B)$ haplotypes in broiler chicken. Animal Genetics, 28, 258-267. 1997.

Li L, Livant EJ and Ewald SJ. The MHC of a broiler chicken line : serology, B-G Genotypes, and B-F/B-LB sequences. Immunogenetics, 49, 215-224. 1999.

Livant EJ, Zheng D, Johnson LW, Shi W and Ewald SJ. Three new MHC haplotypes in broiler breeder chickens. Animal Genetics, 32, 123-131. 2001.

Nordskog AW, Pelzer IY and Lamont SJ. Subregions and functions of the chicken major histocompatibility complex. Poultry Science, 66, 790-794. 1987.

Pazderka F, Longenecker BM, Law GRJ, Stone HA and Ruth RF. Histocompatibility of chicken populations selected for resistance to Marek's disease. Immunogenetics, 2, 93-100. 1975.

Pink JRL, Droege W, Hala K, Miggiano VC and Ziegler A. A three locus model for the chicken major histocompatibility complex. Immunogenetics, 5, 203-216. 1977.

Rothschild MF. Selective breeding for immune responsiveness and disease resistance in livestock. AgBiotech News and Information, 3, 355-360. 1989.

Salomonsen J, Marston D, Avila D, Bumstead N, Johansson B, Juul-Madsen H, Olesen GD, Riegert P, Skjodt K, Vainio O, Wiles MV and Kaufman J. The properties of the single chicken $M H C$ classical class II alpha chain (B-LA) gene indicate an ancient origin for the DR/ E-like isotype of class II molecules. Immunogenetics, 55, 605-614. 2003. 